\section{Mitigating the COVID-19 pandemic in India: an in-depth exploration of challenges and opportunities for three vulnerable population groups}

\author{
Joe Thomas \\ MIT-WPU, Pune, India \\ Emma Emily de Wit \\ Athena Institute, VU University, Amsterdam, The Netherlands \\ R.K. Radhakrishnan \\ The Banyan Academy of Leadership in Mental Health, Chennai, India \\ Nupur Kulkarni \\ MIT-WPU, Pune, India, and \\ Joske G.F. Bunders-Aelen \\ Athena Institute, VU University, Amsterdam, The Netherlands
}

Mitigating the COVID-19 pandemic in India

Received 2 September 2020 Revised 16 May 2021 Accepted 27 May 2021

\begin{abstract}
Purpose - The COVID-19 pandemic is certain to have an unprecedented impact on the global population, but marginalized and vulnerable groups in low-income countries (LICs) are predicted to carry the largest burden. This study focuses on the implications of COVID-19-related measures on three population groups in India, including (1) migrant laborers (of which a majority come from Scheduled Castes (SCs) and Scheduled Tribes (STs), as well as Other Backward Classes (OBCs)), (2) children from low-income families and, (3) refugees and internally displaced persons (IDPs).

Design/methodology/approach - This study adopts a sequential mixed-method research design. A deskbased study of a selection of government reports was undertaken on the COVID-19-related mitigation measures. The desk study was followed by in-depth interviews with purposively recruited high-ranking experts in specific sectors of policy implementation and service delivery across the country.

Findings - The outcomes of this study shed light on (1) the most urgent needs that need to be addressed per population group, (2) the variety of state-level responses as well as best practices observed to deal with mitigation issues and (3) opportunities for quick relief as well as more long-term solutions.

Practical implications - The COVID-19 pandemic has not only reduced people's means of maintaining a livelihood but has simultaneously revealed some of India's long-standing problems with infrastructure and resource distribution in a range of sectors, including nutrition and health, education, etc. There is an urgent need to construct effective pathways to trace and respond to those people who are desolate, and to learn from - and support - good practices at the grassroot level.

Originality/value - The current study contributes to the discussion on how inclusive public health might be reached.
\end{abstract}

Keywords COVID-19 pandemic, India, Mitigation, Marginalized groups, Equality

Paper type Research paper

(C) Joe Thomas, Emma Emily de Wit, R.K. Radhakrishnan, Nupur Kulkarni and Joske G.F. BundersAelen. Published by Emerald Publishing Limited. This article is published under the Creative Commons Attribution (CCBY 4.0) licence. Anyone may reproduce, distribute, translate and create derivative works of this article (for both commercial and non-commercial purposes), subject to full attribution to the original publication and authors. The full terms of this licence may be seen at http://creativecommons. org/licences/by/4.0/legalcode

The authors are indebted to the Tata Institute of Social Sciences in Mumbai for their support in data collection and analysis. The authors furthermore thank all the experts in this study for sharing their invaluable perspectives on the COVID-19 pandemic in India.

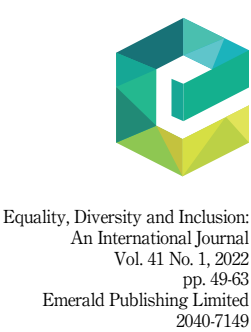

DOI 10.1108/EDI-09-2020-0264 


\section{EDI}

41,1

\section{Introduction}

The COVID-19 pandemic began as a public health emergency and soon became a global humanitarian crisis. The analysis of a complex public health challenge like COVID-19 pandemic calls for a sophisticated, transdisciplinary approach, drawing on ideas and insights from public health, ethics, development studies, economics, sociology, anthropology, law and international relationships (e.g. Gostin and Berkman, 2007). Because pandemics can have a severe destructive effect on national economic and social functioning, scholars agree that there is no "one-size-fits-all" ethical framework to organize countermeasures (e.g. Prehn and Vahter, 2008, p. 1). Still, the dominant driving force behind COVID-19-related public health plans and policies seems so far to have been informed by bio-medical and epidemiological approaches, raising questions about why there has not been more consideration to contextualizing public health responses, particularly in the context of low-and middle-income countries (LICs and MICs), such as India.

Indeed, some of the consequences of India's lockdown, which has been largely copied from wealthier countries, are already pointing to a human catastrophe that reaches far beyond the direct medical consequences of COVID-19, with homeless people being driven off the streets, and millions of daily wage workers being forced to return to their families in the rural areas, often walking miles without sufficient food and drink. Not long after the lockdown commenced, numerous suicide cases have been reported as a result of the COVID-19 measures, as well as an increased fear that "hunger will kill us before Corona does" (e.g. BBC, 25 March 2020).

While the global community has agreed to an ambitious goal of "leaving no one behind", and meeting all of the 17 Sustainable Development Goals (SDGs) by 2030, perhaps one of the criteria for assessing the impact of the COVID-19 pandemic must be on how it will affect the capacity and willingness of nations to continue to integrate goals related to, for instance, health, poverty reduction, elimination of hunger and equality. If state and local governments are to mitigate the public health impact of pandemics, they must give systematic attention to a range of issues, some of which include principles of basic human rights, fairness and antidiscrimination/stigmatization (Gostin and Berkman, 2007; Smith et al., 2019). During pandemics, state authorities are accountable for protecting citizens' health and obliged to use strict measures, such as isolation and social distancing, to "flatten the curve" and reduce the public health risk. Unfortunately, each of these measures raises serious ethical and human rights concerns. It is in this rather extreme context of high public threat that that the concept of "health" itself, which over the years has become more holistic and now integrates psychosocial, economic, ecological and cultural dimensions, is under pressure, as decision-makers are forced to "consider and prioritize potentially competing ethical values" (Smith et al., 2019, p. 798). This is why some scholars have written about "choke-points", or complex ethical issues, that are presented when mitigating a pandemic (Gostin and Berkman, 2007), as well as the role of inter- and transdisciplinary collaboration in preparing for pandemic outbreaks (e.g. Assmuth et al., 2020; Hinchliffe, 2015). Gostin and Berkman (2007, p. 799), for instance, write in relation to pandemic mitigation:

Limits on individual freedom may be necessary to protect the community as a whole as well as those individuals whose liberty is restricted, yet individual liberty should be restricted with great care and only when alternative approaches are unlikely to be effective. In determining these restrictions, the guiding principles should include adopting the least restrictive practices, ensuring that restrictions are necessary and proportional to the need for protection, and ensuring that those affected by restrictions receive support from the community, such as job security and provision of necessities for the individuals and their families. Diverse public voices should be involved in determining the need for restrictions and in articulating their ethical justifications. Furthermore, planning and implementation should be done by decision makers who are impartial and neutral and who are consistent in applying standards, and those affected by the decisions should have a voice in making 
them — and, where feasible, agree in advance to the process. All who are affected by these decisions should be treated with dignity and respect.

What pandemics seem to show, above all, is the challenge of upholding the standards of inclusion and integration when governments need to take urgent and restrictive measures (Smith et al., 2019). With more than 100 nations involved in containing a quickly spreading virus, such as COVID-19, "health needs tend to overwhelm the available human and material resources required to meet those needs" (p. 797). Some countries might be particularly inclined to take protectionist actions and apply containment strategies that restrict universal human rights. Still, insofar that this is possible, the international community as well as specific governments have a shared responsibility to commit to ethical principles of fairness and inclusion that inspired the SDGs, paying special attention to vulnerable populations when implementing restrictive public health measures (Silva et al., 2013). The World Health Organization (WHO) states in its report on ethical considerations regarding pandemics (2007):

Policy-makers should pay specific attention to groups that are the most vulnerable to discrimination, stigmatization or isolation, including racial and ethnic minorities, elderly people, prisoners, disabled persons, migrants and the homeless.

Measures of isolation and "social distancing", which have been a common response to the threat of a pandemic or similar situation, clearly show the potential impacts on vulnerable groups, and should thus be considered in that light. Various scholars (e.g. Gostin and Berkman, 2007; Loades et al., 2020) explain that social isolation can cause mental health problems, loneliness and also disrupt social and economic life. It might be particularly difficult for those who are vulnerable to find protection and go to places where they have access to food, shelter and medical care. In a country such as India, one might ask what are the possible implications of the need to "maintain social distance" not only at a practical level but also at a social-cultural level (considering the stark class divides and notions of untouchability that mark the nation's very recent history).

The current study aims to focus on the implications of COVID-19-related measures on marginalized and vulnerable groups in India. We specifically look at three important population groups across the country, including (1) migrant laborers (of which a majority come from Scheduled Castes (SC) and Scheduled Tribes (ST), as well as other backward classes), (2) children of low-income families and (3) refugees and internally displaced persons (IDPs). While exploring the mitigation efforts at a national and state government level is ambitious, this article evaluates specific policies and how they have succeeded or failed to serve these population groups. In the following section, we present the methods used to conduct this study.

\footnotetext{
Methodology

Research approach

The exploratory qualitative research approach that underpins this study is focused on exploring the research questions in a broad fashion, without intending to offer final and conclusive recommendations. Because the topic is relatively urgent and new, an exploratory research approach was considered appropriate to address the problem of mitigation in India and gain a broad understanding of the nature of challenges involved in protecting public health in relation to vulnerable groups during the pandemic. The chosen methodological orientation, including qualitative in-depth interviews conducted with experts, allowed the researchers to ask open-ended questions and alter the direction of the interview in response to the interaction with the interviewees and the insights they introduced (Saunders et al., 2012). The outcomes to this study are also expected to be indicative of a range of possible challenges and solutions rather than arriving at a fixed and conclusive solution.
} 
EDI

41,1

\section{Data collection}

This study also combined desk-based research and in-depth interviews with experts in specific fields. The desk research, based on a thorough Internet search, was conducted by three researchers at the TATA Institute of Social Sciences (TISS) in Mumbai. The data collected comprised official government organizations (GOs), press conferences of Union Ministers, Chief Ministers and senior officials and tweets from official handles, all related to COVID-19 mitigation efforts, nationally and at state level, between 1 March 2020 and 27 April 2020.

For the qualitative part of this study, ten in-depth interviews were conducted with professionals and lay experts in the field of public health administration, policy development (national or state level), science or development aid (e.g. non-government organizations, NGOs) working at the grassroots with one of the vulnerable groups that concern this study. Experts were considered relevant when they were in a senior position (at least 10 years' experience) and were closely involved in or informed about the developments regarding the COVID-19 pandemic in India. Specific inclusion criteria were:

(1) Professionals who are involved in ground-level service delivery, whether related to public health or other services, such as education, child development, sanitation and hygiene, migration, etc.

(2) People who are knowledgeable of and working closely with vulnerable groups in the country, e.g. SC, ST or OBC, children, migrants or refugees.

(3) People who, because of their working background, have insights into the translation and implementation of government policies related to COVID-19 in various contexts.

(4) As much as possible, people from different parts of the country, representing different states.

Experts were recruited from Kerala, Maharashtra, Karnataka, Rajasthan, Delhi, Madhya Pradesh and Tamil Nadu. The participants included four women and six men, both professionals and lay experts, and were chosen based on their professional profile (mostly) and partly through informal networks and snowball sampling (Naderifar et al., 2017).

\section{Research process and analysis}

All interviews were conducted during the pandemic and via Zoom. The interviews were conducted on various themes related to policy implementation, challenges regarding mitigation, impact of COVID-19 on specific groups and opportunities for development (see Appendix to see what kind of questions were asked). Each interview lasted approximately 90 minutes and was conducted by two primary researchers.

A report was established by sharing the objectives and direction of the study, and offering opportunities to engage more continuously with the research. The interviews were recorded and transcribed verbatim, and summaries were shared with the participants for member checking. The interviews were analyzed through a series of open- and then axial coding. First, the two primary researchers read the transcripts independently to produce a list of codes, which were subsequently discussed and compiled into one list of codes, themes and categories. The final code list was used to analyze the transcripts again and discussed with the entire team before drawing up the results.

The data collected by the TISS-team were analyzed to draw up tables on (1) how COVID-19 infections evolved in all Indian states, (2) what measures were taken at state level to curtail the pandemic and (3) what state-level mitigation efforts were made to support vulnerable people. The data were discussed by the team before being organized in tabular form for the results section. 
Ethics

Informed consent was taken according to APA standards, informing the participants about the purpose of the research, expected duration and procedures and their right to withdraw from the research at any point. The data were stored by the primary researchers and secured with a password. Some of the participants were working at high administrative levels and would have been easy to identify. Their anonymity was preserved by not revealing the names or any relevant information associated with their identity. The validity of the outcomes of this study was preserved by the triangulation between the desk study and the qualitative interviews, thus increasing the reliability of the data.

\section{Results}

In this study, we aimed to explore in which ways the Government of India set out to protect the country against the threat of the COVID-19 pandemic, and, more significantly, what efforts were made to mitigate the impact of COVID-related measures on the most vulnerable groups in India. Considering the magnitude of the issue, as well as the plethora of measures undertaken at national and state level, we were inclined to focus on three specific groups, including migrant laborers, children and refugee and/or displaced groups. Similarly, we followed the threads of some specific policies and schemes to see how successful these are in reaching and supporting these groups. Demographic information on all the experts involved is this study is provided in Table 1.

\section{Mitigation efforts and their impact on vulnerable groups (migrant laborers, children and refugees)}

At the beginning of the pandemic, which became evident in March, it was observed that states used different logistics and policies to distribute aid, such as increasing general ration quotas for specific groups of people (50\% in Delhi, for instance), such as paying INR 1000 for laborers registered under the Construction Labor Welfare Board (e.g. Telangana, Tamil Nadu, Haryana, Punjab, Rajasthan and Meghalaya) and rations for eligible beneficiaries (e.g. Jammu and Kashmir, Kerala, Karnataka and Odisha). Some states opened up specific shelters, camps and/or free food points/kitchen/canteens to support the poor (e.g. Tamil Nadu, Telangana, Karnataka, Jharkhand and Maharashtra). Rajasthan aimed to provide relief for families affected by COVID-19, in addition to INR 1000 per month per family, with social pensions. Most states started providing free food at fair price shops (sometimes for up to six months; some have extended this to November 2021); for instance, in West Bengal and Uttar Pradesh, free grains are provided for 8.3 million widows and disabled persons, and packages of rice, dahl and oil to unorganized workers in Tamil Nadu. Students were supported in various ways by states such as Delhi, Odisha and Madhya Pradesh, to reduce their stress (e.g. by providing money for Internet data in Delhi and mid-day meal coupons in Odisha). Finally, most of the existing policies under the Mahatma Gandhi National Rural Employment Guarantee (MGNREG) were enhanced either by releasing funds in advance and/or supplementing them with some extra financial support.

The question is, how far are these measures and policies successfully implemented and to what extent do they reach the right people. This question was posed to various experts working with migrant laborers, children and refugees, to gauge their opinion on how the needs of these population groups are served.

Migrant laborers. The COVID-19 pandemic has revealed the atrocious living conditions of migrant laborers in the country, as well as the lack of attention to the factors that pressured millions to migrate on foot to their homes in rural areas, at times leading to death. Migrant laborers have been forced out of their villages, in various states of the country, for decades, 
EDI
41,1

\begin{tabular}{lllll}
\hline & Academic background & Professional role & $\begin{array}{l}\text { Years of } \\
\text { experience }\end{array}$ & Geography \\
\hline 1 & $\begin{array}{l}\text { PhD. in Population Studies } \\
\text { and Inclusion }\end{array}$ & $\begin{array}{l}\text { Specialist in policy and } \\
\text { advocacy, particularly in the }\end{array}$ & $20+$ & $\begin{array}{l}\text { National level and } \\
\text { Kerala }\end{array}$
\end{tabular}

\section{4}

area of migration and displacement. Founder of a center focused on migrant issues in India. Advisor and evaluator of grassroot programs for refugees and internally displaced persons

$2 \quad \mathrm{PhD}$ in Sociology focused on the inclusion of tribal and scheduled castes

3 MA in Social Work

4 MA in Medical and Psychiatric Social Work and Public Health. Experience in a large number of emergency and disaster contexts

$5 \quad \mathrm{PhD}$ in International Public Heath

6 MA in Sociology

7 MA in Journalism

8 Bachelor of Engineering

9 Bachelor of Economics
Table 1.

Demographic background of the study participants
Assistant professor in sociology and anthropology.

Worked in policy implementation at various institutions as advisor Project Coordinator at a large international NGO focused on children's well-being $\mathrm{PhD}$ researcher, coordinator and advocate at a national center for child and adolescent health, and women development Diplomat, educator, academic and human rights activist. Worked for WHO; currently coordinating master programs in SDGs at a University in India. Experience in M\&E in South-east Asia regarding sexual and reproductive health and AIDS prevention

Founder and director of international NGO focused on girls and women's development in India

Political reporter for the Hindu and Frontline

An Indian Services Officer (Civil), currently CEO of Zilha Parishad, Pune district

A young fellow at Brihn Mumbai Municipal Corporation (BMC), a part of COVID-19 taskforce. Responsible to maintain an inventory of COVID 19 beds at special care hospitals in Mumbai. Experiences in working with marginal communities in urban and tribal Maharashtra
10 years Kerala and Madhya Pradesh

$\begin{array}{ll}15+\text { years } & \text { Rajasthan } \\ 15+\text { years } & \begin{array}{l}\text { National level and } \\ \text { Karnataka }\end{array}\end{array}$

20 + years National level and Maharashtra

$13+$ years National level and Maharashtra

\section{0 years Tamil Nadu}

10 years National level and Maharashtra Cadre

5 years Maharashtra 


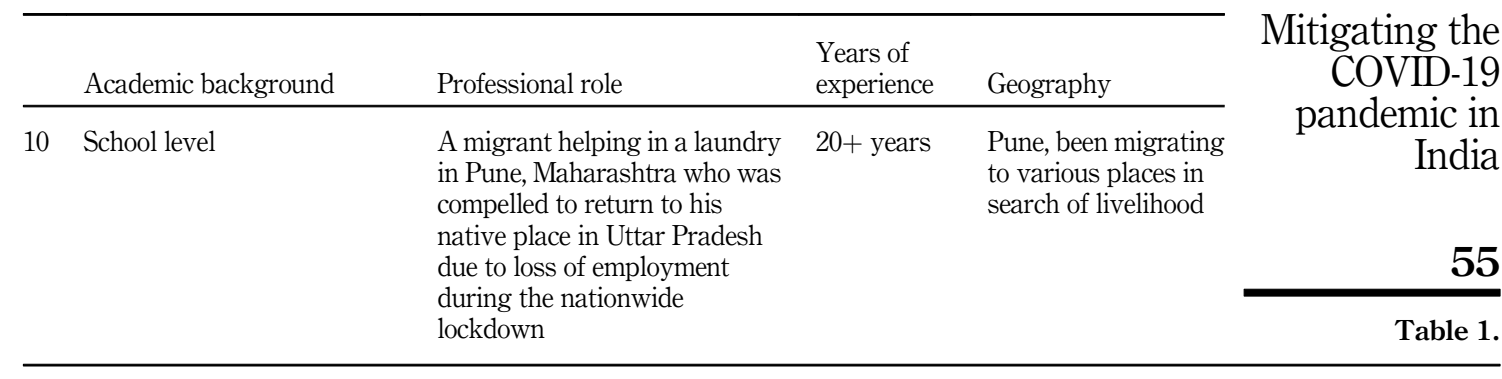

particularly among SCs, STs and OBCs. For instance, a rapid study conducted by the Center for Migration and Inclusive Development (CMID) and Gram Vikas, after the lockdown in Odisha, revealed that in at least one out of three households there has a history of labor migration in the past ten years, and that most of them are from SCs or OBCs. Most of them worked outside their own state, for wages ranging from INR 100 to 200 per day, in states such as Kerala, Tamil Nadu, Karnataka and Goa. During the lockdown, 95 migrants, who were earlier included in a study by CMID, were traced by phone to see where they were residing. In April 2020 , about $54.6 \%$ of this group had arrived back at their original village, after a long journey mostly on foot. Most arrived recently, while some came during the first wave in February. Others were still left at their workplace $(35.8 \%)$ and the rest $(9.5 \%)$ were not traceable. Most had heard about COVID-19, but were ignorant of the prevention measures to be taken or the symptoms of the disease.

The $\mathrm{CEO}$ of the CMID explains that migration has been the backbone of India's economy and should therefore be acknowledged as such. Most migrants are driven out of their rural homes because they lost their land and agricultural livelihoods for a variety of reasons, including to large-scale industries, often developed by the country or its corporate sector. They come to work in construction or in factories in order to send remittances to their families, meanwhile contributing informally to the development of the country. However, the government has done very little to inform or take care of these migrant laborers, leaving them to make irrational decisions or decisions that are not necessarily good for their families. The CEO of CMID explains this predicament:

Generally, what we know is that migration is not a priority for the country and the government is more focused on industry. Of course, rural India has a majority of people that are struggling. And there are many issues related to government. There are issues with employment, livelihood, etc. For migrants, most importantly, what we should do and is done too little, is providing information and support decision making on whether to stay back (in the cities) or to go home. Generally, it is better for themselves and the families if they stay and try to keep up their work, and this is also what we advise them. Also, the health system is often poorer in the rural areas. If people do want to go back, however, they should be provided with free transport and food, to prevent people from dying on route. And the Supreme Court should pressure the government to secure this. Food and accommodation.

The migrant laborers will have no option but to return home, even without the financial means to travel by train or bus. And this will again increase contagion. Regarding the measures that do work, and should be enhanced, various experts gave their opinion. In general, the MGNREGA scheme, as well as other labor-related policies was mentioned as programs that should be enhanced and used to increase the purchasing capacity of the poor. People should get cash in hand, to ensure that the informal economy is somewhat preserved. Unfortunately, in April, only $20 \%$ of the people who were provided work in 2019 were guaranteed to receive salary under the MGNREGA. Some laborers receive an enhanced 
EDI

41,1

payment, but the highest amount is INR 220 a day, which is not enough for a family. The work under MNREGA is limited to 100 days a year per person in a family.

A migrant employed in Maharashtra who was forced to return to his home in Uttar Pradesh explains that he had no option but to arrange for his travel back to his village. His employer did his best to support him financially in the first phase of 21 days after lockdown, but it was difficult as the lockdown continued. In addition, it was near to impossible for him and other migrant workers living with him to maintain social distancing and hygiene practices in their poor housing facility. He added: "There was a great uncertainty about how long the lockdown be in force and survival in my city, without any monthly income flowing in, was too expensive".

Most experts were appalled by the fact that the carefully established labor laws and security measures, drawn up to protect informal laborers, may be suspended to allow more flexibility to business owners and employers, and curb the impact of COVID-19 on the economy. This has already been done in some states and was of great concern for most of the experts we interviewed. The professor from IGNTU:

In the long term, the post-COVID society will not be similar to the previous standard of living and there will be a new normal. But how do we plan for that? How do we ensure safe work place interactions and sustainability of livelihoods?

Finally, we asked what opportunities there were to improve the situation of migrant laborers and their families. Almost all experts referred to civil society, better networks and distribution of resources, and essentially "connection" to support people. The program manager of the child welfare organization in Rajasthan felt that the local state governments are working relatively well with NGOs, and the target groups that are usually included in schemes and programs that support the poor are monitored and cared for. There is, however, the utmost concern for laborers and their families that are out of sight. CEO of CMDI:

Because India has very limited capacity to really respond, and is showing little interest, we need to get on our feet. And some are already responding. Yet, it is a difficult situation. NGOs are also receiving less funding in this crisis. So, the capacity of civil society organizations to respond to the migrant situation is also limited. What is difficult, furthermore, is that migrants, because of the language barriers, and because their employers are sometimes actively hiding them, do not have access to information and services. We cannot reach them easily. They go to services that are somehow affordable to them, which are cheap in quality and might make them even more sick. So, these issues are there. I can tell you there are only 15 to 20 organizations that are good and working on the migrant issues in India, and we are ourselves even relatively young. We try to reach out and provide information through mobile units. We have covered about 20,000 migrant workers now and linked them to health services, as well as provided information in three to five languages.

Drawing on the results of the situation in Odisha, only about $20 \%$ of migrants who plan to return to the rural areas are able to sustain themselves, emphasizing again the need for cash transfers to migrants who are stranded, as well as those who are unsupported, at least to pass through the no-working period (estimated to be at least three months). Tele-counseling, or providing long-distance information, was also offered as an important immediate solution. Finally, improving livelihood options, through flexible loan systems and skills training, will allow migrants a choice in working abroad rather than being forced to do so.

Children in low-economic contexts. Children are, of course, a broad population group, and their experiences of growing up and developing will differ significantly, depending on the unique blend of risk and protective factors in their respective family and wider social context. Financial stability in the family is just one factor that directly and indirectly affects children, but, as experts in this study emphasized, the importance of financial well-being in families is magnified in light of the COVID-19 pandemic. Children who are growing up in low-economic contexts are, according to experts, more exposed to diverse problems that were not fully 
addressed before the pandemic. Issues such as child labor, early marriage, malnutrition, trafficking and exposure to sex-work, as well as domestic violence (physical, sexual and psychosocial abuse) are very likely to worsen in the coming years. Besides, it is likely that the inequality between children who have access to education through Internet and TV, and children who rely on attending school, will increase due to the lockdown. These are a few issues were highlighted by experts. A public health worker and academic at the child and adolescent department of a psychiatric institute, explained:

So now, my primary concern is about these people who are most economically vulnerable and the children who belong to these groups. What newspapers generally look at are the economic part and there are a lot of economic analyses on slow recovery, and so on, because the country was already not doing so well before. The growth was slow, but nobody is really looking at the household economy and consequently the impact of how household economy on children. Anything that creates sudden economic shock, basically leaves families and households that are vulnerable to recalibrate and to think of the use of their already meagre resources. When parents look at the household expenditure patterns, one of the things they tend to do is perceive their children as economic assets. This is one of the reasons also that girl children are seen as a burden, and inferior, because they cost a lot of money through the dowry system. So, the girls are married off quicker. Another thing, such as dowry, as the girl grows older and older, you will have to pay more dowry and you get less bride price. So that's another part. The other of course more obvious one is child labor. Education is going to be one of the first factors that is reduced, and then children are send off to work. Children always become an invisible part of the work force. So, when adults lose their jobs, child employment increases. They could be employed in the informal economy, like street work and domestic help, but also to sex work.

According to experts, it is important to realize that children will be better protected if their family is protected. So again, economic revival, protecting labor laws and cash transfers to vulnerable families are prioritized over more ad-hoc support programs for children. Children, according to the expert at the national institute, do not need, for instance, psychological support right now. Their families need economic support, and if they still cannot manage, then the families should have some sort of alternative option, such as temporarily sending their children to child centers. The program manager adds to this that some existing policies, such as the nutrition schemes of "one meal a day" and "pre-school feeding" should not be discontinued but offered in alternative manner, such as home delivery or by offering grains and other food supplies to families. And the amounts should be sufficient and consistently supplied, which, according to our interviewees, is wholly lacking.

Unwanted pregnancies have also occurred because of the lockdown. The director of an NGO focusing on improving the lives of girls and women, explained:

We have an adoption center, and normally we have good connections with maternity professionals who connect us for guardianship. But many more teenage girls have had to give birth at home. We have had a couple of babies come to our center who were just left on the streets. We managed to find one of the girls who threw the baby away, who was only fourteen years old.

Regarding policies and schemes that might work for children and adolescent girls, most experts again seem skeptical about the capacity and willingness of the government to improve the situation. Experts stress that children would be better protected in the long term if social workers had greater capacity to reach them and undertake careful risk assessments. There is a need to build an infrastructure and to train staff and decision-makers in child welfare committees in order to support families that are at risk of abusing their children in one form or another.

Refugee groups. Refugee groups and IDPs without legal permanent leave to remain in the country are regarded as a high-risk group as the pandemic spreads. The experts in our study were mostly from Tamil Nadu and provided detailed information on how the situation has developed for refugee groups in the state, including Sri Lankan Tamils, Rohingyas and

Mitigating the COVID-19 pandemic in India 
EDI

41,1

Tibetan refugees. The problems mentioned earlier also affect these groups, but there are important differences between the degree of help these groups can receive from local governments and civic organizations. The experts thus raised particular concerns about refugees who are dispersed in the cities and are currently residing outside the designated camps. One journalist, closely connected to the Tamil Nadu State Government Department of Rehabilitation, said:

Essentially all refugee groups are vulnerable in these times of pandemic. But after studying the response from the local agencies, we observed that some of the groups that were located in camps, and speak some Tamil or Hindi, such as the Tibetan refugees and Sri Lankan Tamils, were less neglected. We had to prompt and meditate, but there were some dry rations distributed, as well as medicines that boost immunity. The Rohingyas speak a smattering of Bangla and a little Hindi, and barely manage to access help. Here, the presence of the UNHCR is a big relief for both the non-camp Tamils and the Rohingyas.

The difficulty that many refugees in camps face is that the money that they were receiving from the work they did outside the camps - such as painting, for instance - has vanished. Most painters make about INR 1000 a day (most manage to get between INR 15,000 and INR 20,000 a month) from painting houses and apartments, places of worship or offices. Now, they do not have these extras and are more dependent on what the government gives them. The non-camp refugees are mostly self-employed in small businesses such water-can suppliers, photographers, assistants in service apartments, brokers agents of real estate or marriage, informal work as painters/tailors, etc. Unless they have saved up money, they have no other form of social security. Most of these refugees live in urban areas by renting houses and sending their children mostly to private schools. Generally, it is assumed that most of the noncamp refugees receive remittances from relatives living in other countries. But in recent years, remittances have dwindled. The journalist expert said:

An important priority now is to find those people who are displaced and do not live in camps. They need to be detected and, if needed, supported in similar ways as the other groups.

\section{Discussion}

The COVID-19 pandemic has done much to reveal the catastrophic outcomes of a largely underfunded health system. The Lancet (2020) framed the situation as: "a much needed wakeup call to the necessity of long-term changes to India's health system". Similarly, other scholars have shown how COVID-19 revealed existing inequalities and malfunctions of the health system in India (e.g. Goyal et al., 2020; Sarkar et al., 2020). This article aims to contribute to academic debate by highlighting the transdisciplinary nature of the concept of health, as described in the introduction, and the level of integration and collaboration that is required to care for every member of India's society, starting with the most vulnerable and excluded but also indispensable for all population groups in the country.

The expert opinions presented in this study, focusing mainly on the atrocities experienced by migrant laborers in response to the pandemic, emphasize the general neglect of informal laborers that has prevailed in India for some time. The massive migration witnessed in India, with over 50 million people traveling back to their birth villages, will continue to put an enormous strain on the labor supply in urban areas, as well as a constraint on trade and production levels which are necessary to maintain the economy. Government measures to curtail the pandemic, without necessarily preparing the ground for those who would be deprived of their means to sustain their families, have been described by the experts consulted in this study as failing to acknowledge the vital role that informal workers, including SCs, STs and OBCs, play in sustaining the country's economy. These tendencies to ignore the poor as irrelevant are described as revealing a pre-existing split between the 
higher- and lower income classes. This view is also reflected by other scholars, including, e.g. Rahman (2020), who has stated with regards to the pandemic:

In recent times, India has witnessed a sharp rise in social inequities and economic precarity with the unemployment rate reportedly at its highest in four decades, and discontent and public outrage ensuing state repression. . .Yet the Indian government, when not obfuscating, directed its resources at more aggressive handling of risks rather than looking for truly viable and sustainable alternative (p. 131).

Indeed, as the data in this study also reflect, the actions of the central government, as well as the majority of state governments, were mostly concerned with curtailing the pandemic from a biomedical or evidence-based perspective, using various measures of control to keep the public from meeting each other by observing "social distancing". However, public health measures are rarely apolitical, and, as the situation in India shows, can be experienced as forms of exclusion and repression. As argued by the participants of this study, in refusing to properly compensate, first of all, the country's informal workers and their families, the burden of "social distancing" has been shown to be harshest for those who were already among the most disadvantaged before the pandemic (Barnett-Howell and Mobarak, 2020). Refugee groups and IDPs have become more vulnerable under the veil of social distancing and lockdown as they already lived at subsistence level before COVID-19 and are currently barred from accessing aid facilities (see also UNHCR, 2020). In general, while COVID-19 is often referred to as the "great leveler", the experience of social distancing in India shows that existing inequalities due to historically practiced "vertical distancing" have been exacerbated as a result to "neutral" social distancing measures (e.g. Gopalan and Misra, 2020).

What other scholars have offered as a partial solution is the concept of a universal minimum income in India (e.g. Pulla, 2020), which might be unattainable for a country with a high number of poor people and rapidly growing economic problems (Shah and Jani, 2019). What was most often suggested by the participants in this study is to acknowledge the interdependence of people of all income levels in India and to rediscover, strengthen and leverage the way people rely on each other for their existence (particularly during a pandemic). Such ideas have also been argued in relation to the SDG agenda (see, for example, Filho et al., 2020) and global health systems (Shamasunder et al., 2020). The latter suggests a new paradigm of global health should be imagined, guided by real collaboration, solidarity and equity. Similarly, several scholars and others have argued that the term "social distancing" should be replaced by "physical distancing", allowing for "solidarity, responsibility and cooperation, as well as social closeness" (Kumar et al., 2020).

In general, there should be an attempt to improve the social care, health care and povertyalleviation infrastructure in all states across India. This is not excessively expensive: Kerala, Tamil Nadu, Karnataka, and to some extent states such as Goa and Punjab, have such facilities which have absorbed the worst shocks of the pandemic. The Government of India should constitute a pan-India council, much like the council on Goods and Services Tax, and encourage states to share their models on social infrastructure, health care and poverty alleviation. This does not mean that what worked in one state will work in another, and solutions will need to be contextualized in order to be sustainable (Regeer et al., 2016). Each model should be tailored to local conditions, and each level of governance should be involved in decision-making to ensure that: (1) hunger is tackled, (2) jobs are ensured, (3) health needs are catered for and (4) social stigma is addressed sensitively. The government should be sensitive to local views and caste relations in a given area and also make this an inclusive approach at the local level. While the MNREGA still remains the most relevant piece of legislation to ensure that the very poorest get at least 100 days of unskilled labor, the fact remains that in a pandemic, this has proved inadequate, given the long periods of enforced lockdown. Such a council should also debate the effectiveness of the Public Distribution
Mitigating the COVID-19 pandemic in India 
EDI

41,1

System, and there should be active support from the central government to plug the leaks in the system, and make it effective, and responsive.

Best practices observed in (non-governmental) agencies and civil society acting to support vulnerable population groups can be used as a model for the future (see also Nemteanu and Dabija, 2020). While globally the pandemic has sparked populism (Filho et al., 2020) and stimulated governments to reduce support for NGOs, they should probably provide more support and leeway to access their target groups and collaborate with civil society as they still manage to reach those in most need of help. The problem in India is that, under the PMCARES fund, many NGOs have lost substantial funds from Corporate Social Responsibility (CSR) sources, creating an existential crisis for many (EconomictimesIndia, 2020; July 12). This is unfortunate as studies show that against the backdrop of the pandemic crisis, NGOs and civil society play an essential role in supporting vulnerable people (e.g. Nemteanu and Dabija, 2020; Sreenivasulu, 2020). Our study shows that, for all vulnerable groups, NGOs and civil society have already been seen as a significant actor, most of them continuously active during the pandemic, but they lack support to effectively reach those are desolate and isolated.

Finally, while social distancing, lockdown and curfews have been shown to prevent people from helping their neighbors, activists, students and families should be allowed to support those in need in every way possible. Innovative means should be established to monitor support to those who are isolated as being socially connected helps in times of crisis (including by providing food, groceries, transport, emotional support and, as shared also by one of our experts, information and decision-making power). Opportunities might be found in the experience of Mobile Health and other services provided through mobile applications and networks as most people, even the poor, have a mobile phone or access to one. Several studies have reported on the potential of digital health care and mobile phone support as a response to the pandemic (see, e.g. Gopalakrishnan et al., 2020; Oliver et al., 2020; Kapoor et al., 2020), which is supported by this study. Digital infrastructure, supported by physical care, might empower communities by providing them the right information, guidance and protection, and thus reduce the burden on the health system. As observed in this study, some states (e.g. Kerala) that have a history of social security and support, and had earlier invested in the necessary infrastructure and networks, were more predisposed to respond to the pandemic, by mobilizing Panchayat leaders, local agencies, etc. It might be true that the general culture and political orientation in Kerala, one of the historically more socialist states, inspired its response to the needs of the people during a crisis, in a country that is currently generally oriented toward neo-liberalism.

\section{Conclusion}

COVID-19 teaches us that we are indivisibly linked to one another, and that poor health outcomes affect us all. Acknowledging and acting on the idea of interdependency and interrelatedness might help to create win-win situations that work inclusively. More connection and support for migrant and informal workers, who are indispensable for improving the postpandemic economy, to stay in the cities. Supporting families' livelihoods, ensuring that children remain connected to school and receive their daily meals, serve development goals that intersect closely with the objective of public health. The middle class and the rich cannot afford to ignore the well-being of those who are poorer as they themselves are dependent on their existence to maintain their own. As such, the Prime Minister's plea for families to support as many other families as possible, and for companies to refrain from firing their workers, is relevant, but not enough. The robustness of Kerala's health infrastructure, despite the high infection rates, has taught policy makers that there are no shortcuts to a healthy population. In thickly populated countries such as India, there is no choice but to remain ever vigilant of communicable disease 
outbreaks across the world, also during the second wave of the pandemic as currently observed in the country. Empowering the existing organizations to be on the lookout, predict, draw up models and constantly interact with all tiers of governance, should form an essential part of strategy, going forward. Best practices as portrayed in this study could serve as a template for reframing health systems that work for everyone, and activate governments to support grassroots organizations and civic agents that are disposed to maintain connections with the most vulnerable.
Mitigating the COVID-19 pandemic in India

\section{References}

Assmuth, T., Chen, X., Degeling, C., Haahtela, T., Irvine, K.N., Keune, H., Kock, R., Rantala, S., Rüegg, S. and Vikström, S. (2020), "Integrative concepts and practices of health in transdisciplinary social ecology", Socio-Ecological Practice Research, Vol. 2 No. 1, pp. 71-90.

Barnett-Howell, Z. and Mobarak, A.M. (2020), "The benefits and costs of social distancing in rich and poor countries", Working paper, arXiv preprint arXiv:2004.0486.

Filho, W., Brandli, L.L., Lange Salvia, A., Rayman-Bacchus, L. and Platje, J. (2020), "COVID-19 and the UN sustainable development goals: threat to solidarity or an opportunity?", Sustainability, Vol. 12 No. 13, p. 5343.

Gopalan, H.S. and Misra, A. (2020), "COVID-19 pandemic and challenges for socio-economic issues, healthcare and national programs in India", Diabetes and Metabolic Syndrome: Clinical Research and Reviews, Vol. 14 No. 5, pp. 757-759.

Gopalakrishnan, L., Buback, L., Fernald, L., Walker, D., Diamond-Smith, N. and in addition to The CAS Evaluation Consortium (2020), "Using mHealth to improve health care delivery in India: a qualitative examination of the perspectives of community health workers and beneficiaries", $\mathrm{PloS}$ One, Vol. 15 No. 1, e0227451.

Gostin, L.O. and Berkman, B.E. (2007), "Pandemic influenza: ethics, law, and the public's health", Administrative Law Review, Vol. 59, p. 121.

Goyal, M.K., Simpson, J.N., Boyle, M.D., Badolato, G.M., Delaney, M., McCarter, R. and Cora-Bramble, D. (2020), "Racial/ethnic and socioeconomic disparities of SARS-CoV-2 infection among children", Pediatrics, Vol. 146 No. 4.

Hinchliffe, S. (2015), "More than one world, more than one health: re-configuring interspecies health", Social Science and Medicine, Vol. 129, pp. 28-35.

Kapoor, A., Guha, S., Das, M.K., Goswami, K.C. and Yadav, R. (2020), "Digital healthcare: the only solution for better healthcare during COVID-19 pandemic?", Indian Heart Journal.

Kumar, K., Mehra, A., Sahoo, S., Nehra, R. and Grover, S. (2020), "The psychological impact of COVID19 pandemic and lockdown on the migrant workers: a cross-sectional survey", The Asian Journal of Psychiatry, Vol. 53, 102252, doi: 10.1016/j.ajp.2020.102252.

Loades, M.E., Chatburn, E., Higson-Sweeney, N., Reynolds, S., Shafran, R., Brigden, A., Linney, C., McManus, M.N., Borwick, C. and Crawley, E. (2020), "Rapid systematic review: the impact of social isolation and loneliness on the mental health of children and adolescents in the context of COVID-19", Journal of the American Academy of Child and Adolescent Psychiatry, Vol. 60 No. 60, pp. 6-7.

Naderifar, M., Goli, H. and Ghaljaie, F. (2017), "Snowball sampling: a purposeful method of sampling in qualitative research", Strides in Development of Medical Education, Vol. 14 No. 3, pp. 1-6.

Nemțeanu, M.S. and Dabija, D.C. (2020), "Best practices of nongovernmental organisations in combatting COVID-19", New Trends in Sustainable Business and Consumption, ASE, Messina, Bucharest, pp. 626-633, 4-6 June.

Oliver, N., Lepri, B., Sterly, H., Lambiotte, R., Deletaille, S., De Nadai, M., Letouzé, E., Salah, A.A., Benjamins, R., Cattuto, C. and Colizza, V. (2020), "Mobile phone data for informing public health actions across the COVID-19 pandemic life cycle", Science Advances, Vol. 6, p. 23. 
EDI 41,1

Prehn, A.W. and Vawter, D.E. (2008), Ethical Guidance for Rationing Scarce Health-Related Resources in a Severe Influenza Pandemic: Literature and Plan Review, Minnesota Department of Health, Minnesota.

Pulla, P. (2020), “Covid-19: India imposes lockdown for 21 days and cases rise”, BMJ, Vol. 368, m1251.

Rahman, S.Y. (2020), "Social distancing' during COVID-19: the metaphors and politics of pandemic response in India", Health Sociology Review, pp. 1-9.

Regeer, B.J., de Wildt-Liesveld, R., van Mierlo, B. and Bunders, J.F. (2016), "Exploring ways to reconcile accountability and learning in the evaluation of niche experiments", Evaluation, Vol. 22 No. 1, pp. 6-28.

Sarkar, P., Debnath, N. and Reang, D. (2020), "Coupled human-environment system amid COVID-19 crisis: a conceptual model to understand the nexus", The Science of the Total Environment, Vol. 753, p. 141757.

Saunders, M., Lewis, P. and Thornhill, A. (2012), Research Methods for Business Students (6. Utg.), Pearson, Harlow.

Shah, K.K. and Jani, D.G. (2019), "A preliminary survey of the theoretical and practical aspects of UBI and assessing its feasibility in the context of the Indian economy", Arthshastra Indian Journal of Economics and Research, Vol. 8 No. 4, pp. 47-55.

Shamasunder, S., Holmes, S.M., Goronga, T., Carrasco, H., Katz, E., Frankfurter, R. and Keshavjee, S. (2020), "COVID-19 reveals weak health systems by design: why we must re-make global health in this historic moment", Global Public Health, Vol. 15 No. 7, pp. 1-7.

Silva, D.S., Smith, M.J. and Upshur, R.E. (2013), "Disadvantaging the disadvantaged: when public health policies and practices negatively affect marginalized populations", Canadian Journal of Public Health, Vol. 104 No. 5, pp. e410-e412.

Smith, M.J., Thompson, A. and Upshur, R.E. (2019), "Public health as social justice? A qualitative study of public health policy-makers' perspectives”, Social Justice Research, Vol. 32 No. 3, pp. 384-402.

Sreenivasulu, G. (2020), "The role of Media”, NGO's and Civil Society in Covid-19.

UNHCR (2020), IOM, UNHCR Announce Temporary Suspension of Resettlement Travel for Refugees, available at: https://www.unhcr.org/news/press/2020/3/5e7103034/iom-unhcr-announcetemporary-suspension-resettlement-travel-refugees.html.

\section{Appendix}

\section{In-depth interview guide}

We would like to talk to you about the developments and measures that were conducted around the COVID-19 virus in India. We would like to start broadly to talk about the measures at national level and their implications, but would also love to hear about your impressions at state-level and what has evolved ever since the virus became acknowledged as a public health threat in India. Finally, we would like to discuss with you the future implications of the government responses to COVID-19.

(1) Could you shortly introduce how and why you are connected to policy development and implementation in your own particular context.

(2) With regards to the developments of the COVID-19 in India, what are your more general impressions?

(3) At national level, how do you feel about the guidelines regarding COVID-19? Could you elaborate on what you perceive are the quality of the national measures in general?

(4) With regards to the preparedness of the country for a lock down, what do you feel went well and what was missing? Could you give specific examples? 
(5) What measures for mitigation would you have expected at national level that were or were not introduced?

(6) How do you relate to the concept of "social distancing" and what it means for a country like India, considering it's unique historical and cultural context?

(7) What specific suggestions would you have given to the government of India to protect the country from a public health threat without hurting the livelihood of vulnerable people?

Let us have a look at the measures that were conducted at state level.

(8) Could you explain a bit more on what more specific measures and interventions were taken in your respective state?

(9) Would you say that these measures and developments differed much or not considerably from other states in the country?

(10) Could you elaborate on what could have instigated these variances in response (if any), as to what motivated these specific measures?

(11) How were these intended measures implemented and rolled out? (e.g. did they reach the people they were intending to reach and how?)

(12) What measures were clearly missing according to your knowledge and practice? What would you have expected to see in terms of mitigation or other forms of social support that were not rolled out?

(13) Would you say that there are states that performed better regarding the virus (e.g. Kerela), and what could be learned from these states?

Let us have a look at the future now.

(14) What do you think will be the implications of the measures or lack of measures regarding vulnerable groups in your respective state?

(15) What economic resources are available to improve the country's mitigation and development efforts in times of the pandemic?

(16) How can future pandemics be better prevented, if at all, and or mitigated?

(17) What, according to you, evidence do we already have of the implications and consequences of the current pandemic (whether interventions were effective or not).

Do you have any other comments?

\section{Corresponding author}

Emma Emily de Wit can be contacted at: emmaemilydewit@gmail.com

For instructions on how to order reprints of this article, please visit our website: 